\title{
The N400 as a function of the level of processing
}

\section{DOROTHEE J. CHWILLA, COLIN M. BROWN, AND PETER HAGOORT}

Max Planck Institute for Psycholinguistics, Nijmegen, The Netherlands

\begin{abstract}
In a semantic priming paradigm, the effects of different levels of processing on the N400 were assessed by changing the task demands. In the lexical decision task, subjects had to discriminate between words and nonwords, and in the physical task, subjects had to discriminate between uppercase and lowercase letters. The proportion of related versus unrelated word pairs differed between conditions. A lexicality test on reaction times demonstrated that the physical task was performed nonlexically. Moreover, a semantic priming reaction time effect was obtained only in the lexical decision task. The level of processing clearly affected the event-related potentials. An N400 priming effect was only observed in the lexical decision task. In contrast, in the physical task a P 300 effect was observed for either related or unrelated targets, depending on their frequency of occurrence. Taken together, the results indicate that an N400 priming effect is only evoked when the task performance induces the semantic aspects of words to become part of an episodic trace of the stimulus event.
\end{abstract}

Descriptors: Levels of processing, Semantic priming, N400, P300

In this study, we investigated the influence of task demands on the $\mathrm{N} 400$ semantic priming effect. In particular, we focused on the impact on the $\mathrm{N} 400$ of different levels of processing of lexical stimuli. In this report, we first discuss the relevant semantic priming effects and the mechanisms responsible for these priming effects then we introduce the levels of processing framework within which semantic priming effects were investigated.

One of the most consistent findings in the psycholinguistic literature is that words are processed faster and more accurately when they are preceded by a semantically related or associated word than by an unrelated word (e.g., Meyer \& Schvaneveldt, 1971; see Neely, 1991, for a review). More recently, it has been demonstrated that semantic priming effects can also be recorded with the use of the event-related brain potential (ERP) method. Kutas and Hillyard $(1980,1984)$ identified an ERP component, the $\mathrm{N} 400$, a negative peak with a mean latency of $400 \mathrm{~ms}$ and a centroparietal distribution, that is larger in amplitude for words that are semantically incongruent with a preceding sentence context. Subsequent research has shown that the N400 is tied more to semantic expectancy than to anomaly (e.g., Kutas, Lindamood, \& Hillyard, 1984).

This research was supported by grant 560-256-048 from the Netherlands Organization for Scientific Research (NWO).

We thank Marta Kutas, two anonymous reviewers, and Tony Gaillard for helpful comments on earlier versions of this paper. We are also grateful to Johan Weustink for technical assistance and to Inge Doehring and Uli Chwilla for graphical support.

Address reprint requests to: Dorothee J. Chwilla, Nijmegen Institute for Cognition and Information, P.O. Box 9104, $6500 \mathrm{HE}$ Nijmegen, The Netherlands.
A modulation in $\mathrm{N} 400$ amplitude as a function of semantic context is not only obtained in sentences but also when a single word provides the context (see Kutas \& Van Petten, 1988, for a review). If a target word is preceded by a semantically related prime, it elicits a smaller $\mathrm{N} 400$ than when it is preceded by a semantically unrelated word (e.g., Bentin, McCarthy, \& Wood, 1985; Holcomb, 1988; Holcomb \& Neville, 1990; Kutas \& Hillyard, 1989). This difference in amplitude is referred to as the N400 priming effect. Because of the sensitivity of this ERP component to language processes, the $\mathrm{N} 400$ has been used as a new measure for psycholinguistic research (Kutas \& Van Petten, 1988). It is by now well established that the amplitude of the N400 varies as a function of the degree to which the eliciting word relates to its preceding semantic context. On the basis of the literature, however, it is less clear which processing aspects of the language comprehension system are reflected in the N400.

In functional models of word recognition (e.g., Frauenfelder \& Tyler, 1987; Marslen-Wilson, 1989; Zwitserlood, 1989), three processes are commonly distinguished: lexical access, selection, and integration. Lexical access involves the process of computing a form representation of the physical signal and of mapping this representation onto corresponding entries in the mental lexicon. This processing results in the activation of a subset of lexical elements and their semantic and syntactic attributes. The process of selection refers to the process of selecting from the subset of accessed elements the element that best matches the input available to the system. Integration refers to the process of integrating a lexical element into a higher order meaning representation of the entire sentence or discourse.

Within this functional model of word recognition, lexical access is conceived of as a reflexlike automatic process. In con- 
trast, lexical integration is thought of as a more controlled process that can be guided by the subject's awareness of the informational content of the discourse and that requires more processing resources than does lexical access. However, at the same time lexical integration is a mandatory process (Fodor, 1983); in normal discourses, subjects of necessity engage in the integration of individual word meanings into message-level representations.

To assess the value of the N400 as a measure for psycholinguistic research, how the $\mathrm{N} 400$ relates to these different lexical processes must be clarified. A well-defined testing ground within psycholinguistics for clarifying this issue is that of semantic priming (cf. Neely, 1991). From the vast amount of reaction time semantic priming studies, a fairly well-developed picture has emerged of the mechanisms responsible for priming effects. According to Neely and Keefe (1989), at least three mechanisms are needed to account for the full spectrum of reaction time priming effects.

The first mechanism is automatic spreading of activation (ASA; Collins \& Loftus, 1975). ASA assumes that in semantic memory strong or direct links exist between words that are closely related in meaning. Presentation of a word activates the corresponding node of this word in semantic memory, and via the links to nearby nodes part of this activation automatically spreads to words that are related in meaning. As a consequence, the activated nodes representing related words need less time for subsequent processing. ASA has all the characteristics of an automatic process. It is fast acting, of short duration, does not require attention or awareness, and presupposes no or only minimal resource capacity.

The second mechanism is expectancy-induced priming (Becker, 1985; Posner \& Snyder, 1975). This is a predictive strategy in which the subject uses the information provided by the prime to generate an expectancy set for related target words. If the target is included in this set, it will be recognized more quickly. If it is not, the recognition for the target word will be slowed down. This mechanism can be influenced by instructions as well as by the list structure of the material. Especially when the stimulus list contains a large proportion of related word pairs, the probability that the expectancy mechanism contributes to the overall priming effect is large (Keefe \& Neely, 1990).

The third priming mechanism is semantic matching (De Groot, 1984; Neely \& Keefe, 1989). If letter strings are processed lexically, subjects are assumed to mandatorily match primes and targets postlexically (i.e., following lexical access and selection) for semantic similarity. In a lexical decision task, the word/nonword decision is influenced by the result of this matching process. The detection of a relationship between primes and targets leads to a bias to respond yes. If no such relation is detected, then there is a bias to respond no.

In summary, three mechanisms are supposed to underly semantic priming. The assumption is that two of these mechanisms share core characteristics with mechanisms involved in ordinary language processing. That is, ASA shares core characteristics with lexical access, and semantic matching shares core characteristics with postlexical integration processes (De Groot, 1984; Henderson, 1982; Neely, 1991). Insight into the contribution of these different mechanisms to the N400 semantic priming effect will therefore be of substantial value in relating the $\mathrm{N} 400$ to the processes of access, selection, and integration. The aim of the present study was to separate the contribution of these priming mechanisms to the N400 effect in the semantic prim- ing paradigm. In particular, we attempted to separate the effects of ASA from the effects of semantic matching by varying the level of processing.

The levels of processing framework as described by Craik and Lockhart (1972) have often been used to investigate episodic memory. This literature has consistently demonstrated a better recognition and recall for words that have to be processed on the basis of semantic features (a deep level of processing) than for words that have to be processed on the basis of visual or phonemic features (a shallow level of processing; see Jacoby \& Dallas, 1981). The basic idea is that shallow processing of the word stimuli discourages analysis of their semantic aspects. As a result, the semantic context might not be incorporated into the formation of the episodic trace of the stimulus event. If semantic priming effects are nevertheless obtained, they probably result from automatic activation spreading within semantic memory. Consequently, semantic priming effects obtained in a shallow task most likely arise from ASA. In contrast, deeper processing presumably involves the processing of the semantic aspects of the presented words. In this case, the semantic context does exert its influence on the formation of the episodic trace. Because both expectancy-induced priming and semantic matching presuppose the formation of an episodic trace for a particular wordlike stimulus event, priming effects obtained in a situation that is compatible with deeper levels of processing might, therefore, also reflect the effects of these additional priming mechanisms.

In contrast to the popularity of the levels of processing framework within memory research, there are only a few psycholinguistic studies that have assessed the effects of the level of processing on semantic priming. In these studies, the effect of the level of processing was assessed by manipulating the nature of the information (e.g., orthographic, semantic) required to accurately make a lexical decision on target letter strings. This manipulation was done in two ways: (a) by varying the kind of nonwords that were presented as targets (De Groot, 1987; Schulman \& Davison, 1977) or (b) by varying the kind of discrimination required on the prime word (Smith, Theodor, \& Franklin, 1983) or the target word (De Groot, 1987). Taken together, the results of these studies reveal that the semantic priming effect is much larger for tasks that impose a deeper level of processing than for tasks for which a more shallow level suffices. Although the size of the reaction-time priming effects depends on the depth of processing, significant priming effects have also been reported with shallow processing tasks. Smith et al. (1983) obtained a priming effect when a phonemic analysis was performed on the prime. Mitchell et al. (1991) found a reaction-time priming effect in a task in which subjects had to discriminate words on the basis of physical features. These findings demonstrate that the use of shallow processing tasks in itself does not necessarily exclude the processing of a word's semantic aspects.

The levels of processing approach have also been used to determine the processing nature of the $\mathrm{N} 400$. The results of these ERP studies were not conclusive. Some studies demonstrated N400 priming effects with shallow processing tasks (Besson, Fischler, Boaz, \& Raney, 1992; Kutas \& Hillyard, 1989). Other studies, however, did not observe N400 priming effects under shallow processing conditions (Bentin, Kutas, \& Hillyard, 1993; Deacon, Breton, Ritter, \& Vaughan, 1991). The fact that in some studies N400 priming effects have been obtained in shallow processing tasks has been taken as evidence that the N400 is sensi- 
tive to automatic lexical semantic processes (Kutas \& Van Petten, 1988). However, this conclusion critically depends on the claim that the N400 priming effects obtained in these shallow processing tasks cannot be attributed to priming mechanisms other than ASA. To examine this issue these studies will be described in more detail.

Kutas and Hillyard (1989) obtained an N400 priming effect in a letter search task. In this task, the first word was followed after a stimulus onset asynchrony (SOA) of $700 \mathrm{~ms}$ by the second word, which in turn was followed after $1,200 \mathrm{~ms}$ by a single letter. Subjects had to indicate whether the letter had been present in either or both of the words. In response to the second word, an $\mathrm{N} 400$ priming effect was observed. Although Kutas and Hillyard (1989) correctly assumed that performing this task does not require semantic processing, subjects may still have matched the words for semantic similarity. The delay between the presentation of the words and the moment subjects were asked to respond might have given subjects ample opportunity to in fact perform some kind of semantic matching, in which case the observed $\mathrm{N} 400$ priming effect does not necessarily stem from ASA. A similar argument holds for the study of Besson et al. (1992), in which subjects had to indicate whether the first and the last letter of two words that were presented with an SOA of $300 \mathrm{~ms}$ were the same or different. In this task, a small $(<1 \mu \mathrm{V})$ but reliable $\mathrm{N} 400$ priming effect was observed. The authors attributed this small N400 priming effect to automatic lexical semantic processing. However, because the subjects were also required to perform memory tests on the stimuli, paying attention to word meanings was probably reinforced by the design.

The contrasting results of various studies testing the effects of depth of processing on the $\mathrm{N} 400$ and the $\mathrm{N} 400$ priming effects obtained with shallow levels of processing in some studies might reflect the fact that the shallow task did not in all cases effectively prevent the occurrence of semantic matching. Alternatively, these shallow $\mathrm{N} 400$ priming effects might result from ASA. To decide between these two possibilities, more objective criteria are needed to ascertain whether the performance of a particular task involves lexical processing. One objective method is computation of the lexicality effect, that is, the difference in overall reaction times between all word and all nonword targets. In general, words are responded to faster than are nonwords. In models of word recognition, lexicality effects are attributed to operations at a lexical level of processing (cf. De Groot, 1987).

The aim of the present study was to separate the effects of ASA from the effects of semantic matching on the N400 priming effect by varying the level of processing. It was assumed that N400 priming effects for tasks that are compatible with deeper levels of processing are mediated by ASA and by semantic matching. In contrast, N400 priming effects for shallow processing tasks were assumed to exclusively reflect ASA. To control for task-related levels of processing, we established whether or not the task performance depended on lexical characteristics of the presented letter strings. If the task were performed nonlexically, that would suggest that indeed the task discourages semantic analysis. If $\mathrm{N} 400$ semantic priming effects were obtained in the absence of a reaction time lexicality effect, then this N400 effect would most likely be due to automatic spread of activation in semantic memory.

In the current study, the effects of the level of processing on the reaction time and the N400 measure was assessed by comparing the processing of the same words and nonwords in a lex- ical decision task and a physical task. The choice of the tasks was based on previous studies that demonstrated differences in ERPs between a lexical decision and a physical task. In these studies, a clear reduction in the size of repetition priming (Rugg, Furda, \& Lorist, 1988) and semantic priming effects (Mitchell et al., 1991) was observed for the physical task, which required subjects to respond on the basis of certain physical aspects of the letter strings. Therefore, it was assumed that the level of processing for the two tasks is different. A visual word priming paradigm was used, in which a prime word was followed after $700 \mathrm{~ms}$ by a target word. The level of processing was manipulated by varying the target discrimination between tasks. In the lexical decision task, the target discrimination was based on a word/nonword discrimination. In the physical task, the target discrimination was based on purely physical features (letter case), which does not require lexical processing. The use of the lexical decision task does not necessarily guarantee access to word meaning, because this task could be performed solely on the basis of the word form. However, there is ample evidence from the semantic priming literature that normally this task yields semantic priming effects. Therefore, it is reasonable to assume that the lexical decision task is compatible with semantic analysis, whereas the physical task discourages semantic analysis, because paying attention to the relationship between the words does not help to perform the letter case discrimination.

To test whether the physical task is indeed performed nonlexically, the lexicality effect was assessed. If lexical processing were involved in the task performance, the processing of words would be faster than the processing of nonwords. 'If, however, a task were performed nonlexically, the reaction times to word targets would not be different from the reaction times to nonword targets. In the absence of a reaction time difference between words and nonwords, we can address the question of whether an N400 priming effect occurs when the task performance does not involve lexical processing. The absence of a lexicality reaction time effect does not necessarily imply that semantic aspects of the stimuli go unnoticed at all levels of the processing system. Whether or not these aspects are processed to some degree must be inferred from the ERP waveform. If the ERP data allow us to infer that semantic processing has gone on at some level in the language system, then we can use the presence or absence of $\mathrm{N} 400$ effects to make claims about the priming mechanisms that the $\mathrm{N} 400$ is particularly sensitive to. Assuming that we can ensure that the physical task is performed nonlexically, the following predictions can be made. If the $\mathrm{N} 400$ priming effect is mediated by semantic matching and expectancy but not by ASA, we expect an N400 priming effect in the lexical decision task but no effect in the physical task. In contrast, if the N400 effect also reflects ASA, an N400 priming effect should additionally be obtained in the physical task. An N400 priming effect in the physical task would imply that N400 priming effects occur relatively automatically, that is, that they are independent of the task demands.

In addition to the task manipulation, we also varied the proportion of related word pairs in the stimulus list. The propor-

'Although it is an extremely robust finding that words are processed faster than nonwords, there are a few exceptions to this rule. For example, words take longer to process when very low-frequency words are used or if subjects are asked to classify items according to whether they have more than one meaning (see Forster \& Bednall, 1976). 
tion of related word pairs determines the probability that subjects use the prime to generate an expectancy about the target (Keefe \& Neely, 1990). The generation of this expectancy requires access to the semantic aspects of the prime. Contrasting the effects for a list with a small number of related word pairs with those for a list with a large number of related word pairs under both task conditions further allows us to determine whether or not semantic factors leak through under the shallow processing task conditions.

\section{Method}

\section{Subjects}

Thirty-six right-handed subjects, 20 women and 16 men (mean age $=24$ years) participated in the experiment. Hand dominance was assessed with an abridged Dutch version of the Edinburgh Inventory (Oldfield, 1971). Seven subjects reported lefthandedness in their immediate family. All were native speakers of Dutch and had normal or corrected-to-normal vision. They were paid DFL $10 / \mathrm{hr}$.

\section{Apparatus and Stimuli}

Subjects were seated in a comfortable reclining chair in a dimly illuminated, sound attenuating, and electrically shielded chamber. The response device containing two push buttons was fixed on a small table in front of the subjects. The stimuli consisted of 960 visually presented pairs of letter strings (prime and target combinations). Half of the target stimuli were real Dutch words and the other half were nonwords. The nonwords were constructed in accordance with the phonotactic constraints of Dutch and were derived from real words by substituting one or two letters. The word targets were preceded by a related or an unrelated prime (e.g., black-white vs. soap-bird). A pair was considered related if the target appeared as the highest word association to the prime in Dutch word-association norms (De Groot, 1980; De Groot \& de Bil, 1987; Lauteslager, Schaap, \& Schievels, 1986). Associative strength was determined by the percentage of occurrence of the target as an associate of the prime among 100 university students. The mean percentage of association between the prime and the target for the related pairs was $47.41 \%(S D=15.30 \%)$. A pair was considered unrelated if the target neither occurred as a word association of the prime in these norms nor had any other obvious semantic relation to the prime. Strings of three to eight letters were presented as targets. Across conditions, targets were balanced on mean word frequency (Uit den Boogaart, 1975; corpus size 720,000), word class (nouns, adjectives, verbs), and the number of letters and syllables. There was a total of 160 related and 160 unrelated word pairs.

A pilot study was conducted to select a subset of target words from the related and unrelated word pairs that are matched on the basis of reaction times. In this pilot study, word and nonword targets were presented in isolation. Subjects $(n=20)$ performed a speeded lexical decison task: They had to indicate as fast as possible whether the target word was a real word or not. On the basis of these reaction times, 40 related and 40 unrelated word pairs were selected. These pairs are referred to as the critical pairs. (The appendix gives all critical pairs and the mean reaction time and language frequency of the targets.) The mean reaction time for both the critical related and unrelated targets was $506 \mathrm{~ms}$ ( $S D=27.6$ and $28.0 \mathrm{~ms}$ for related and unrelated targets, respectively).
Two lists of 480 prime-target pairs were constructed. One list had a high proportion of related word pairs $(.80)$. The other list had a low proportion of related word pairs $(.20) .^{2}$ The 40 critical related and 40 critical unrelated word pairs were the same in both lists. In the high-proportion list, the critical word pairs were supplemented by 120 related word pairs and in the low proportion list by 120 unrelated word pairs. Two hundred primetarget pairs with a nonword target were added to each list. Additionally, in each list 80 prime-target pairs were included with the Dutch word blank as a prime; half of these were followed by a real word and the other half were followed by a nonword. These pairs were used as fillers in this experiment.

In the lexical decision task primes and targets were presented in uppercase letters. In the physical task, primes were in uppercase letters, whereas half of the word and nonword targets were presented in lowercase and the other half in uppercase letters. All critical targets were presented in uppercase letters. The stimuli were presented at moderate contrast at the center of a PC monitor (window of $8 \times 2 \mathrm{~cm}$, white on black). The stimuli subtended a visual angle of approximately $3^{\circ} \times 0.8^{\circ}$.

The electroencephalogram (EEG) was recorded with $\mathrm{Ag} /$ $\mathrm{AgCl}(d=9 \mathrm{~mm})$ electrodes monopolarly from three midline positions $(\mathrm{Fz}, \mathrm{Cz}, \mathrm{Pz})$ and two pairs of lateral electrodes. Symmetrical anterior temporal electrodes were placed halfway between F7 and T3, and F8 and T4 sites, respectively. Symmetrical posterior temporal electrodes were placed lateral (by $30 \%$ of the interaural distance) and $12.5 \%$ posterior to the vertex. The left mastoid served as reference. Electrode impedance was less than $3 \mathrm{k} \Omega$. The electrooculogram (EOG) was recorded bipolarly using four $\mathrm{Ag} / \mathrm{AgCl}(d=6 \mathrm{~mm})$ electrodes. The vertical EOG was recorded by placing an electrode above and below the right eye. The horizontal EOG was recorded via a right-to-left canthal montage. EEG and EOG signals were amplified by Nihon Kohden amplifiers (type AB-601G; time constant $=8 \mathrm{~s}$, low-pass filter $=-3 \mathrm{~dB}$ cutoff at $30 \mathrm{~Hz}$ ). A calibration pulse (peak-peak amplitude: $2 \mathrm{mV}$, duration $1 \mathrm{~s}$ ) was recorded before each session. All physiological signals were digitized on line with a sampling frequency of $200 \mathrm{~Hz}$ using a 12 bit A/D converter. Control of the presentation of stimuli and recording of performance data were accomplished by a Miro GD laboratory computer.

\section{Procedure}

Subjects were randomly assigned to task (lexical decision or physical) and list (high proportion or low proportion). Nine subjects were tested in each of the four task/list combinations. Subjects were told that pairs of letter strings would be presented in rapid succession. The first word (the prime) was followed after an SOA of $700 \mathrm{~ms}$ by a second word (the target). The stimulus duration was $200 \mathrm{~ms}$, and the intertrial interval between the offset of the second word and the onset of the first word was $3.2 \mathrm{~s}$. Subjects were asked to pay attention to the second word, the target stimulus. The kind of target discrimination varied as a function of the task.

In the lexical decision task, subjects had to decide whether the target stimulus was a Dutch word or not. If the target was a word, they had to press the response button on the right side;

\footnotetext{
${ }^{2}$ The relatedness proportion in psycholinguistic studies does not refer to the overall probability but is defined as the ratio of related and unrelated word pairs within a list (cf. Neely, 1991).
} 
if not, they had to press the button on the left. They were asked to respond as fast as possible but to remain accurate.

In the physical task, subjects were asked to decide whether the target stimulus was written in upper-or lowercase. If the target appeared in uppercase they had to press the button on the right side, if the target appeared in lowercase they had to press the button on the left side. Subjects were asked to respond as quickly as possible.

In both tasks, subjects gave right-hand (right button press) and left-hand (left button press) responses. To facilitate fast responses and avoid motor artifacts, subjects were asked to keep their index fingers on the response keys. Subjects were not informed about differences in relatedness between the different types of word pairs. The stimuli were presented in two blocks of 240 trials each (mean duration $=16 \mathrm{~min}$ ). There was an interval of 5 min between blocks. A short training session in which the proportion of related word pairs was 0.50 preceded the experimental session. Subjects were trained to speed up reaction time $(<1 \mathrm{~s})$ and to control their eye movements. They were trained to make eye movements approximately $1 \mathrm{~s}$ after the button press and to fixate on the center of the screen in anticipation of the prime-target pairs.

\section{Data Analy'sis}

EEG and EOG records were examined for artifacts and for excessive EOG amplitude during the epoch from $150 \mathrm{~ms}$ preceding the prime to $1 \mathrm{~s}$ after the onset of the target. Only trials in which the EOG amplitude did not exceed $100 \mu \mathrm{V}$ and in which no other artifacts were present were used for averaging. ERPs were averaged time locked to the target, relative to a $100-\mathrm{ms}$ pretarget baseline.

The window for scoring ERP components was based upon visual analysis and depended upon the time interval in which maximal differences between conditions were obtained. The following measures were obtained for each derivation: N400 (average amplitude in the 300-400-ms epoch after the target stimulus) and $\mathrm{P} 300$ (average amplitude in the $400-500-\mathrm{ms}$ epoch after the target stimulus).

Unless explicitly stated otherwise, all analyses were carried out on the 40 critical items per condition only. Analyses of the ERP data involved analyses of variance (ANOVAs) with task (lexical decision, physical task) and proportion (high, low) as between-subject variables and relatedness (related, unrelated) and electrode (Fz, Cz, Pz, anterior temporal bilateral sites, posterior temporal bilateral sites) as within-subject variables. Where interactions with the electrode variable are reported, ANOVAs were performed after performing a $Z$-score normalization procedure to equalize the mean amplitudes across experimental conditions. This normalization procedure is equivalent to the normalization procedure suggested by McCarthy and Wood $(1985) .^{3}$

At the reaction time level, the lexicality effect was assessed to reveal whether the physical task was indeed performed nonlexically. For each subject, the mean reaction time was calculated for correct responses to all word targets, related and unrelated combined (cf. De Groot, 1987). Also, each subject's mean reaction time for all correct nonword target responses was calculated.

${ }^{3}$ The $Z$-score normalization procedure was described by Rösler, Heil, and Glowalla (1993).
To analyze reaction time priming effects, separate ANOVAs were performed for both tasks, with proportion (high, low) and relatedness (related, unrelated). To control for an increase in Type I error in within-subjects tests, the degrees of freedom for the $F$ tests were adjusted using the procedure described by Greenhouse and Geisser (1959; cf. Winer, 1971). The adjusted degrees of freedom and $p$ values are presented. The significance of contrasts was assessed by post hoc Newman-Keuls tests. All effects mentioned are significant at the .05 level or beyond.

\section{Results}

\section{Reaction Time Data}

The lexicality test revealed that the physical task was performed nonlexically, that is, on the basis of nonlexical form information only. In the physical task, no difference in mean reaction time was found between the 240 word targets $(419 \mathrm{~ms})$ and the 240 nonword targets $(416 \mathrm{~ms})$. For the lexical decision task, a lexicality effect was found: reaction times were shorter for word targets $(525 \mathrm{~ms})$ than for nonword targets $(592 \mathrm{~ms})(F[1,16]=$ 99.38, $p<.0001)$.

The reaction time results for the critical word pairs are summarized in Table 1. A priming effect was obtained in the lexical decision task $(F[1,16]=72.05, p<.0001)$ but not in the physical task $(F[1,16]=0.30$, n.s. $)$. In the lexical decision task, a decrease in reaction time was found for related word pairs (519 ms) as compared with unrelated word pairs (559 ms). For the lexical decision task, a Proportion $\times$ Relatedness interaction $(F[1,16]=20.76, p<.001)$ revealed that the priming effect was more pronounced for the high-proportion condition $(59 \mathrm{~ms}$ ) than for the low proportion condition $(21 \mathrm{~ms})$. Post hoc tests demonstrated that the priming effect in the lexical decision task was significant for the high-proportion $(p<.01)$ as well as for the low-proportion $(p<.01)$ condition. In the physical task, no significant differences in reaction times between related and unrelated word pairs were found.

\section{ERPS}

Grand averages for the lexical and the physical tasks and for high and low proportions are presented in Figure 1 and Figure 2 , respectively, in which related and unrelated word targets and nonword targets are superimposed.

Inspection of the waveforms suggests that in the lexical decision task an N400 priming effect clearly developed, which was absent in the physical task. In both tasks, a P300 was evoked, reflecting that a decision was required on the target. The N400 in the lexical decision task was affected by relatedness; larger amplitudes were observed for unrelated than for related targets.

Table 1. Reaction Time (ms) for High-and Low-Proportion Conditions

\begin{tabular}{lccc}
\hline \hline Task & Related & Unrelated & Difference \\
\hline Lexical decision & & & \\
High & 510 & 569 & 59 \\
Low & 527 & 548 & 21 \\
Physical & & & \\
High & 448 & 460 & 12 \\
Low & 404 & 408 & 4 \\
\hline
\end{tabular}


LEXICAL DECISION

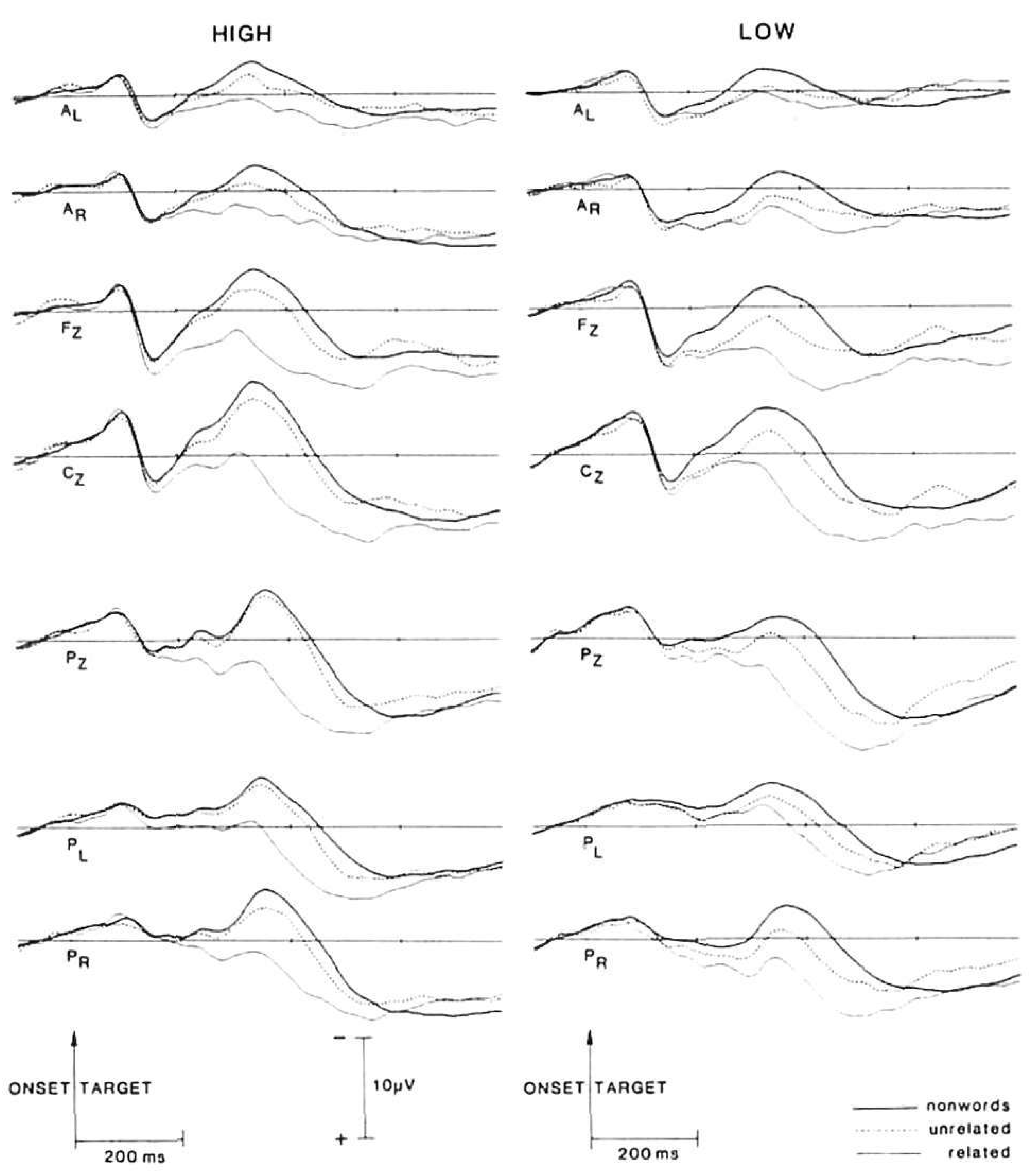

Figure 1. Grand ERP averages of the lexical decision task ( $n=9$ subjects) for the left and right anterior ( $A L, A R)$, the three midline $(\mathrm{Fz}, \mathrm{Cz}$, $\mathrm{Pz}$ ), and posterior (PL, PR) electrodes, superimposed for related (thin line), unrelated (broken line), and nonword (thick line) targets separately for high and low proportion.

The N400 and the P300 were widely distributed. The N400 in the lexical decision task was largest at the vertex, whereas the P300 in the physical task showed maximal amplitudes at Pz.

The main results of the overall analyses are summarized in Table $2 .{ }^{4}$ The main effect of task indicated that overall amplitudes were more positive in the physical than in the lexical decision task, in particular within the $\mathrm{N} 400$ window. The interaction between task and relatedness revealed that the N400 in the lexical decision task was larger for unrelated than for related word pairs, whereas no such difference was found in the physical task. A main effect of proportion within the $\mathrm{N} 400$ window reflected that overall amplitudes were less positive in the high-proportion condition $(2.4 \mu \mathrm{V})$ than in the low-proportion condition $(5.1 \mu \mathrm{V})$. A Task $\times$ Proportion $\times$ Relatedness interaction was present. This interaction revealed that for the two tasks a different interplay between proportion and relatedness was observed.

In addition to the overall ANOVA, semantic priming effects were analyzed for each task separately. These ANOVAs involved proportion, relatedness, and electrode.

Lexical decision task. The ANOVA yielded a significantly larger N400 amplitude for unrelated than for related word pairs

\footnotetext{
${ }^{4}$ Additional ANOVAs with broader latency regions, in which the $\mathrm{N} 400$ was measured as the mean amplitude within the $300-500-\mathrm{ms}$ epoch and the P300 was measured as the mean amplitude of the 400-600-ms epoch, confirmed all effects reported in Table 2.
}

Table 2. F Values for ANOVAs for the N400 and the P300

\begin{tabular}{lccc}
\hline \hline \multicolumn{1}{c}{ Effect } & $d f^{a}$ & N400 & P300 \\
\hline Task & 1,32 & $35.31^{* * *}$ & $8.62^{* *}$ \\
Proportion & 1,32 & $5.97^{*}$ & $\mathrm{~ns}$ \\
Relatedness & 1,32 & $22.13^{* * *}$ & $12.47^{* *}$ \\
Electrode & 1,32 & $15.77^{* * *}$ & $28.26^{* * *}$ \\
Task $\times$ Relatedness & 1,32 & $20.52^{* * *}$ & $22.21^{* * *}$ \\
Task $\times$ Proportion $\times$ Relatedness & 1,32 & $5.81^{*}$ & $7.26^{*}$ \\
Task $\times$ Electrode & 1,32 & $10.43^{* *}$ & $4.77^{*}$ \\
Relatedness $\times$ Electrode & 1,32 & $9.78^{* * *}$ & $5.13^{*}$ \\
& & & \\
\hline
\end{tabular}

Note: Interactions with $p$ values $>.05$ are omitted.

${ }^{a}$ Degrees of freedom were adjusted according to Greenhouse and Geisser (1959).

${ }^{*} p<.05 ;{ }^{* *} p<.01 ;{ }^{* * *} p<.001$.

$(F[1,16]=28.50, p<.001)$. An interaction of Electrode $\times$ Relatedness $(F[1,16]=10.51, p<.01)$ indicated that the N400 priming effect was most pronounced at the midline sites, in particular at $\mathrm{Cz}$ and $\mathrm{Pz}$. The N400 priming effect was smaller at right and left posterior sites and further decreased at lateral anterior sites (Figure 3). The $\mathrm{N} 400$ tended to be larger (about $0.5 \mu \mathrm{V}$ ) above right posterior than above left posterior sites. In parallel

PHYSICAL TASK

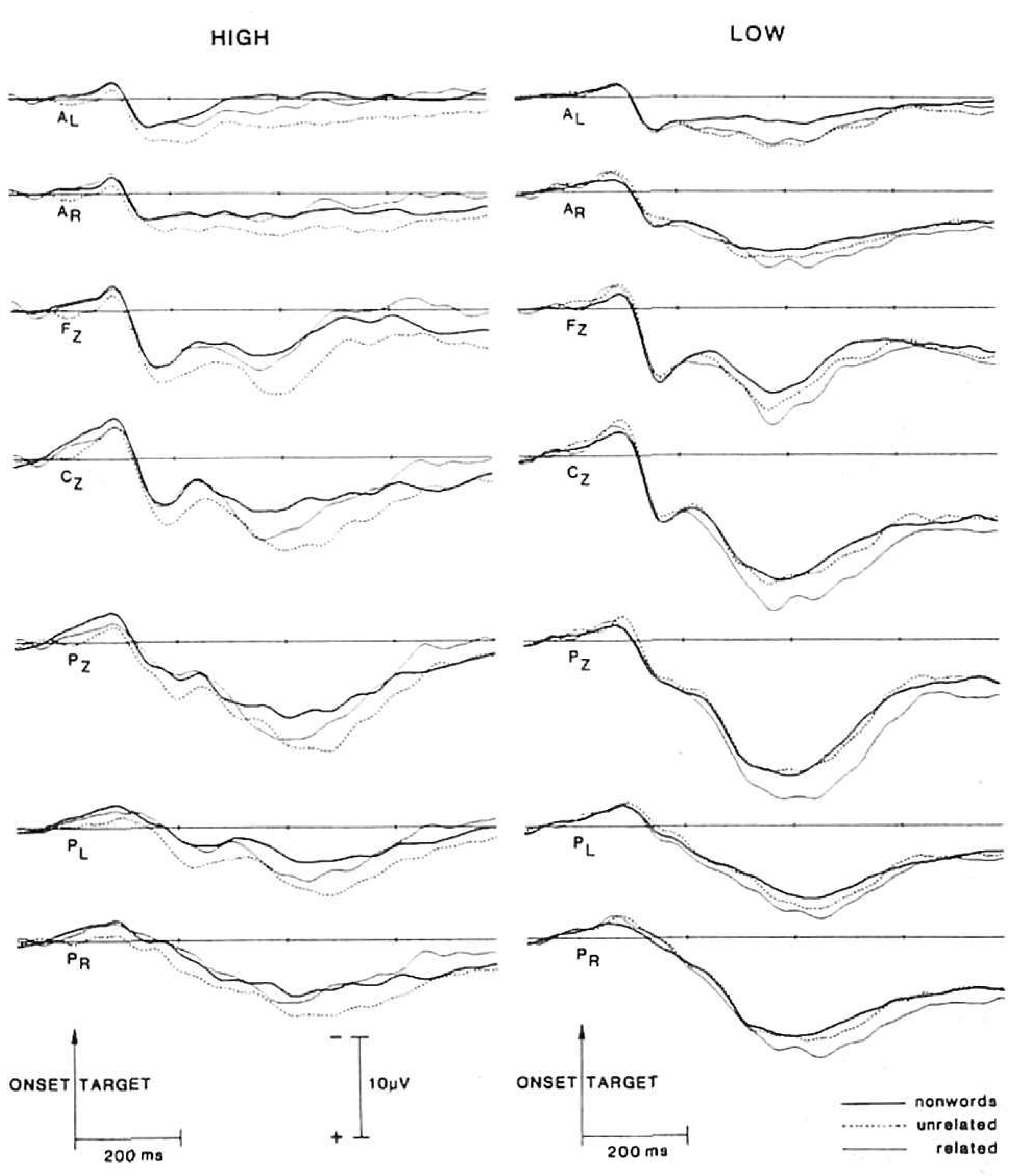

Figure 2. Grand ERP averages of the physical task ( $n=9$ subjects) for the left and right anterior ( $\mathrm{AL}, \mathrm{AR})$, the three midline $(\mathrm{Fz}, \mathrm{Cz}, \mathrm{Pz})$, and posterior (PL, PR) electrodes, superimposed for related (thin line), unrelated (broken line), and nonword (thick line) targets separately for high and low proportion. 
to the reaction time results, Figures 1 and 3 suggest that the difference in N400 amplitude between related and unrelated word pairs was larger for the high-proportion $(4.4 \mu \mathrm{V})$ than for the low-proportion $(2.5 \mu \mathrm{V})$ condition. This increase in priming effect was caused by a larger N400 amplitude for unrelated word pairs than for related word pairs in the high- than in the lowproportion condition. Although in the overall ANOVA the Proportion $\times$ Relatedness interaction was not significant $(p<.20)$, a significant interaction was obtained at the left posterior site $(p<.05)$. In a recent extension of this study with a larger number of subjects $(n=15)$, we observed a similar increase in $\mathrm{N} 400$ priming effect for the high-proportion condition, which was statistically reliable (Brown, Hagoort, \& Chwilla, 1994).

Analysis of the $\mathrm{P} 300$ revealed a main effect of electrode $(F[1,16]=8.14, p<.05)$, with the largest amplitude at $\mathrm{Pz}$. As Figure 1 shows, the $\mathrm{N} 400$ priming effect extends up to at least $600 \mathrm{~ms}$ posttarget, yielding larger P300s for related than for unrelated word pairs $(F[1,16]=28.35, p<.001)$. Therefore overlap of N400 and P300 cannot be excluded. Because of this overlap, it is difficult to assess the effects of the experimental manipulations on the P300 in the lexical decision task.

Physical task. A main effect of electrode was observed for the physical task $(F[1,16]=24.02, p<.001)$. Post hoc tests demonstrated that $\mathrm{P} 300$ amplitude was larger $(p<.01)$ at $\mathrm{Pz}$ than at all other electrodes $(p<.01)$ except $\mathrm{Cz}$.

The P300 was affected by the proportion of related word pairs $(F[1,16]=4.66, p<.05)$; its amplitude was larger in the low-proportion $(9.1 \mu \mathrm{V})$ than in the high-proportion $(5.4 \mu \mathrm{V})$ condition. The ANOVA also yielded an interaction of Proportion $\times$ Relatedness $(F[1,16]=12.18, p<.01)$. This interaction indicated that the P300 was affected by probability (see Figure 3 ). In the high-proportion condition, in which related word pairs were presented with a high probability, P300 was larger in response to unrelated $(6.5 \mu \mathrm{V})$ than to related $(4.2 \mu \mathrm{V})$ word pairs. A post hoc test revealed that this difference in P300 amplitude was significant at the $1 \%$ level. In contrast, in the low-proportion condition, P300 was larger for the infrequent related $(9.7 \mu \mathrm{V})$ than for the frequent unrelated $(8.4 \mu \mathrm{V})$ word pairs. A post hoc test demonstrated that this difference in P300 amplitude was significant at $\mathrm{Pz}(p<.05)$ but not at other electrodes.

\section{Lexicality Test}

To investigate the effect of lexicality, ERPs were averaged separately for word and nonword targets. Separate ANOVAs were carried out for the lexical and the physical task with betweensubject variable proportion (high, low) and within-subject variables lexicality (word, nonword) and electrode (seven levels).

The ANOVAs of the lexical decision task yielded a main effect of lexicality for both the 300-400-ms epoch $(F[1,16]=$ $71.39, p<.0001)$, and the 400-500-ms epoch $(F[1,16]=93.58$, $p<.0001)$. In the early and the late epoch, the waveform was more negative going for nonwords than for words. The lexicality effect was widespread across the scalp, with a trend toward a larger difference between words and nonwords above the right hemisphere.

A significant effect of lexicality was also obtained in the physical task (300-400-ms epoch: $F[1,16]=74.18, p<.0001 ; 400-$ 500-ms epoch: $F[1,16]=65.04, p<.0001)$. In both epochs, the waveform was less positive for nonwords than for word targets. No interaction of proportion and lexicality was obtained, indi- cating that the lexicality effect was of similar size for the highand the low-proportion condition. ${ }^{5}$

\section{Topography of the Priming Effect and the Lexicality Effect}

Inspection of Figures 1 and 2 suggests that there might be topographical differences between the priming effect and the lexicality effect. In the lexical decision task, for instance, both effects result in a modulation of the N400. The priming effect is largest at centroparietal midline sites and much smaller at anterior sites (see also Figure 3). In contrast, the lexicality effect has a more frontal distribution.

To test for possible differential distributions of priming and lexicality effects, for each task separate ANOVAs were performed in which the scalp distributions of the priming effect and the lexicality effect were compared directly. This analysis was performed for the early (N400) and the late (P300) latency region (300-400 ms and 400-500 ms, respectively).

The priming effect was computed by subtracting the mean amplitudes for related targets from the mean amplitudes for unrelated targets. The lexicality effect was computed by subtracting the mean amplitudes for unrelated targets from the mean amplitudes for nonword targets. For each task, ANOVAs were performed on these difference scores, with proportion as the between-subject variable and dimension (semantic vs. lexical) and electrode as within-subject variables.

For the lexical decision task, a marginally significant Dimension $\times$ Electrode interaction was obtained for the early window $(F[1,16]=3.19, p<.10)$ but not for the late window. No significant Proportion $\times$ Dimension $\times$ Electrode interactions were obtained. These results confirm that the N400 lexicality effect was more frontally distributed than the centroparietally distributed N400 priming effect. Also in the physical task, a marginally significant Dimension $\times$ Electrode interaction was obtained for the early window $(F[1,16]=3.62, p<.10)$ but not for the late window.

Whether the distributional differences between priming and lexicality effects have any functional significance is, however, unclear. Because both N400 and P300 generator ensembles seem

\footnotetext{
${ }^{5}$ However, a possible problem is that in the previous test unrelated and related words were collapsed and contrasted with nonwords and that the inclusion of related words confounds the priming effect with the lexicality effect. Therefore, it might be argued that to get a more appropriate estimate of the lexicality effect, nonwords should be contrasted only with unrelated words. To control for the possibility that the lexicality effect actually arises from a confounding with the priming dimension, additional ANOVAs were performed in which only unrelated words were contrasted with nonwords. These analyses essentially revealed the same results. Significant lexicality effects for both epochs were obtained in the lexical decision task (300-400-ms epoch: $F[1,16]=16.89, p<.001$; 400-500-ms epoch: $F[1,16]=17.55, p<.001)$ and also in the physical task (300-400-ms epoch: $F[1,16]=16.91, p<.001 ; 400-500-m s$ epoch: $F[1,16]=23.39, p<.001)$. The only difference with respect to the original analyses was that for the late epoch in the physical task a Proportion $\times$ Lexicality interaction $(F[1,16]=7.37, p<.02)$ was obtained. This interaction indicated that the lexicality effect was more pronounced in the high- than in the low-proportion condition (see Figure 2). However, the probability for nonwords and unrelated words differed between conditions such that in the high-proportion condition unrelated words were presented with a low probability. If the lexicality effect in the physical task is due to a modulation in P300 amplitude, then these differences in probability might affect the amplitude of this positivity. Figure 2 indeed suggests that probability is the most important determinant of the differential amplitude modulation of the positivity.
} 


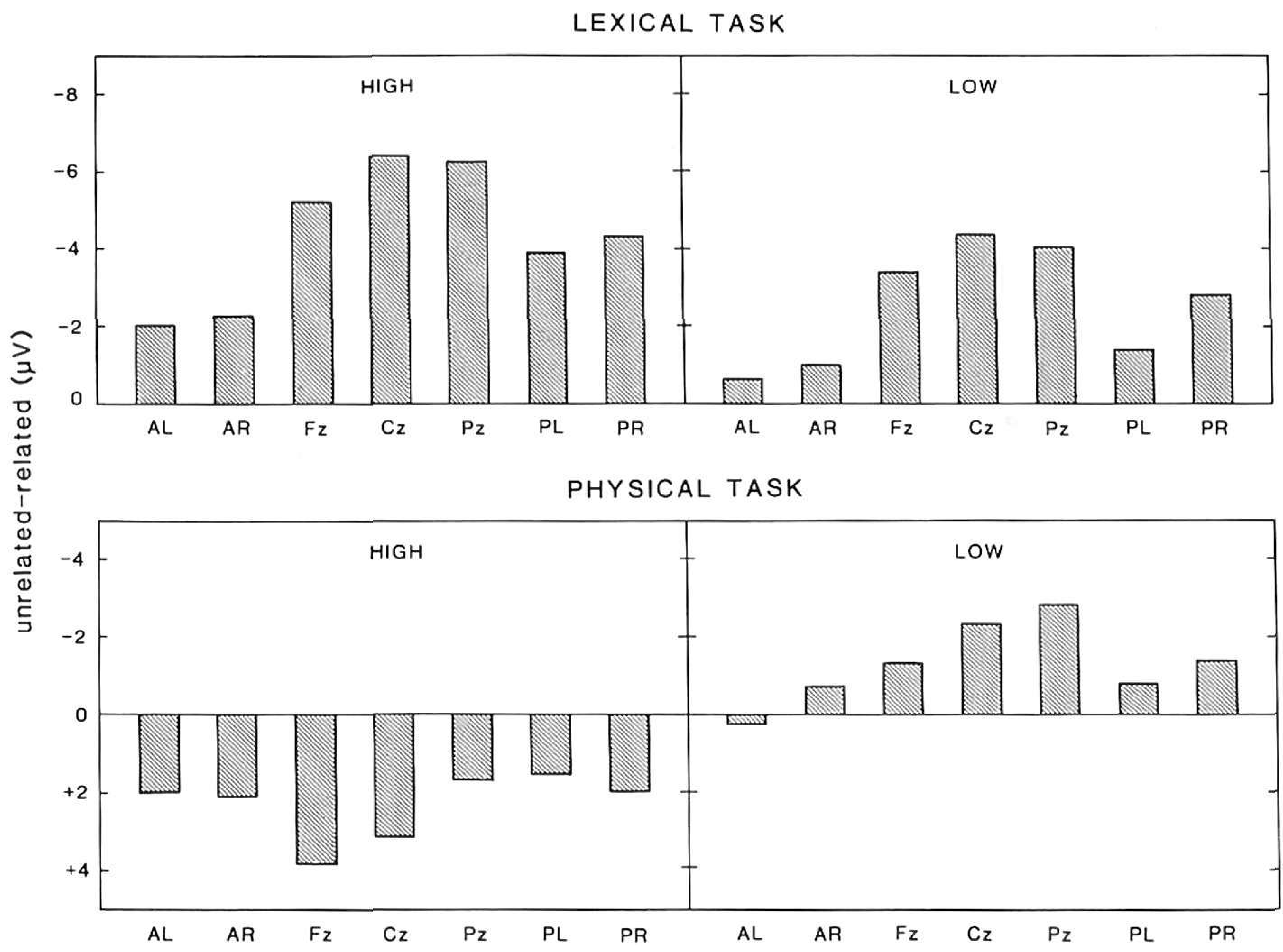

Figure 3. Difference in amplitude between unrelated and related targets for the N400 in the lexical decision task and for the P300 in the physical task separately for the high and the low proportion condition for the three midline $(\mathrm{Fz}, \mathrm{Cz}, \mathrm{Pz})$, left and right anterior (AL, $\mathrm{AR})$, and posterior ( $\mathrm{PL}$, PR) electrodes.

to have their effects in at least partly overlapping time windows, their differential contributions to the waveforms might have resulted in overall topographic differences between lexical and priming effects. It, therefore, seems premature to interpret these differences in a functional sense.

\section{Discussion}

The present findings replicate earlier results that showed that N400 priming effects are evoked in a lexical decision task. The duration of the N400 observed in this study, its topography, and the size of the priming effect are in agreement with those reported in the literature (see Holcomb, 1988; Holcomb \& Neville, 1990). The N400 is also quite similar to the classical N400 observed in sentence completions (Kutas \& Hillyard, 1980).

The goal of this study was to examine which aspects of lexical processing (access, selection, integration) are reflected by the N400 effect. This issue was addressed by assessing the effects of different semantic priming mechanisms on the N400 priming effect. More specifically, we attempted to separate the effects of automatic spreading of activation from the effects of semantic matching by varying the level of processing. We compared the ERPs in a lexical decision task with the ERPs in a physical task. At the reaction time level, the lexicality test indicated that different levels of processing were induced by performing the two tasks. There was no difference in the reaction times for word and nonword targets in the physical task, indicating that this task was performed nonlexically. In contrast, a significant lexicality effect was obtained in the lexical decision task. In addition, a reaction time semantic priming effect was obtained in the lexical decision task but not in the physical task.

After having established that the physical task was performed nonlexically, we can address the question whether an N400 priming effect occurs when the task performance does not involve lexical processing. An N400 priming effect clearly developed in the lexical decision task and was absent in the physical task (Figures 1 and 2). In the lexical decision task, the N400 was modulated by the relatedness of prime and target, yielding much larger amplitudes for unrelated than for related word pairs. In contrast, no indication for an N400 priming effect was obtained in the physical task. Once it is made sure that for task-related performance the target words are processed nonlexically, an N400 priming effect is no longer observed. This result suggests that the modulation of the N400 amplitude requires the explicit identification of a word, including its meaning. If word meaning does not become part of the episodic trace of a particular wordlike stimulation event, N400 priming effects do not seem to arise. This result also lends credibility to the suggestion that previous studies in which $\mathrm{N} 400$ priming effects were obtained in shallow processing tasks (Besson et al., 1992; Connolly, Stewart, \& Philips, 1990; Kutas \& Hillyard, 1989) might have been unsuccessful in preventing explicit identification of the words and their meaning.

\section{N400 Effect and Lexical Processes}

What are the implications of these results with respect to the processing nature of the N400 effect? The absence of an N400 priming effect in the physical task challenges the view that the N400 effect reflects the automatic process of lexical access and its concomitant ASA. This conclusion is further supported by the absence of an N400 priming effect when the prime is masked, thereby preventing conscious identification of the stimulus (Brown \& Hagoort, 1993). The presence of N400 priming effects in the lexical decision task provides further evidence that the $\mathrm{N} 400$ effect is closely tied to lexical integration processes, mediated by the mechanism of semantic matching. Brown and Hagoort (1993) argued that lexical processing in the context of word priming shares core characteristics with the process of lexical integration in the ordinary process of sentence comprehension. That is, once lexical information has been accessed automatically on 
the basis of the speech signal or the orthographic input, the syntactic and semantic information associated with the activated word form has to be integrated with the preceding context into an overall interpretation of the whole utterance. The N400 effect is claimed to reflect this process of lexical integration (see Holcomb, 1993, and Rugg et al., 1988, for similar views).

\section{Processing in the Physical Task}

So far, the results for reaction time and $\mathrm{N} 400$ are compatible with two conclusions: (a) the absence in the physical task of a lexicality effect and a priming effect is due to the fact that nonlexical task performance prevented word meaning from becoming part of the episodic trace, and (b) even accessing word meaning in semantic memory was prevented under the shallow task conditions. This latter possibility is, however, excluded by the $\mathrm{P} 300$ results.

In the physical task, we observed a modulation of the parietally distributed positivity as a function of the probability of related and unrelated word pairs, with larger amplitudes for the stimulus category that occurred with the lower probability (see Figures 2 and 3 ). Both the distribution of this positivity and its sensitivity to the probability of a certain stimulus event suggests that this positivity reflects the $\mathrm{P} 300$ component (see Johnson, 1988, for a review). The important point here is that the P300 results demonstrate that the subjects assigned related and unrelated word pairs to different categories. This assignment presupposes that subjects accessed word meanings when processing the primes and targets. As such, it implies that even in the absence of reaction time and $\mathrm{N} 400$ effects in the physical task, accessing word meaning in semantic memory was not prevented. The more reduced positivity to nonwords as compared with unrelated and related target words fits well with the above picture, because the nonwords were presented with a higher probability $(.50)$ than were both unrelated word pairs (overall probabilities of .08 in the high-proportion condition and .33 in the low proportion condition) and related word pairs (.33 and .08 in high- and lowproportion list, respectively). Although on the basis of these results we cannot fully specify all the dimensions that might have entered into the categorization of the prime-target pairs by the subjects, it seems clear that lexical and semantic characteristics were both involved. ${ }^{6}$

This study was not designed to investigate the relationship between the P300 and lexical processes. Nevertheless, we observed an intriguing dissociation between the reaction time and N400 results on the one hand and the P300 results on the other hand. What might these $\mathrm{P} 300$ effects reflect? A tentative explanation is that the presence or absence (in the case of nonwords) of activation of word meanings in semantic memory and the automatic spread of activation between related nodes in semantic memory might have led to an implicitly generated categorization of stimulus events that became part of the episodic

\footnotetext{
${ }^{6}$ In the P300 literature, the probability effect is often related to the task demands. In the physical task, the probability of the different categories (related, unrelated, nonwords) was not task relevant. However, the P300 probability effect has also been linked to automatic processing. Several results indicate that the relationship between P300 and probability meets criteria for automatic encoding (see Campbell, Courchesne, Picton, \& Squires, 1979; Duncan-Johnson \& Donchin, 1977). Moreover, P300 effects have been reported in neuropsychological patients that did not show behavioral sensitivity to the task-relevant dimension (Renault, Signoret, Debruille, Breton, \& Bolgert, 1989).
}

representation in terms of more likely and less likely stimulus events. That is, the semantic aspects of the words did not themselves become part of the episodic trace (as suggested by the absence of $\mathrm{N} 400$ effects) but led to an explicitly recognized but unspecified sense of more and less frequent stimulation events, resulting in the observed $\mathrm{P} 300$ effects.

\section{Careats}

The above claims can only be made if it can be shown that the observed differences in ERP pattern between tasks could not be ascribed to other factors.

A first, minor consideration is that task difficulty was not controlled across tasks. This resulted in differences in overall reaction times between the lexical and the physical task. It could be argued that the observed differences in ERP pattern between tasks are due to differences in reaction time. However, two aspects of the present data argue against this possibility. First, in the physical task, reaction times were the same for related and unrelated targets and for words and nonwords, whereas there were clear differences in P300. This dissociation suggests that differences in ERPs cannot be attributed in a simple way to differences in reaction time. Second, the fact that different ERP patterns were obtained across tasks, especially the absence of an N400 priming effect in the physical task, supports the idea that the difference in task performance is not of a quantitative but of a qualitative nature.

A second issue concerns component overlap. Because both the N400 and the P300 component occur within roughly the same latency range, it cannot be excluded that both N400s and P300s were present to different degrees across the conditions. The crucial question, however, is whether the main effects of the present study can be explained in terms of component overlap. We first discuss the possible implication of component overlap for the $\mathrm{N} 400$ effects obtained in the lexical decision task and then consider the implications for the P300 effects in the physical task.

Could the N400 priming effect observed in the lexical decision task be explained in terms of an overlapping P300 component? This idea is rejected for the following reasons. In the present study the probability of related and unrelated targets was reversed across conditions (.80/.20 and .20/.80). Because of the inverse relationship between stimulus probability and P300 amplitude, we expect different $\mathrm{N} 400$ patterns across conditions if the P300 is overlapping. Because of the larger P300 for the lowprobability event, the amplitude of the N400 should be reduced to unrelated targets in the high-proportion condition, because unrelated word pairs are only presented in $20 \%$ of the cases. If this were the case, the $\mathrm{N} 400$ for unrelated targets in the highproportion condition would have been smaller than the N400 for unrelated targets in the low-proportion condition. However, the opposite pattern was observed. The N400 for unrelated wordpairs even tended to be larger in the high-than in the low-proportion condition.

The second question is whether the absence of an N400 priming effect in the physical task may be due to overlapping components. Here, a distinction should be made between two different types of overlap. The first concerns overlap of the N400 component with the P300 component, whereas the second concerns an overlap of $\mathrm{N} 400$ priming effects with $\mathrm{P} 300$ probability effects. From the present data, it cannot be excluded that an N400 component was evoked that overlapped the P300 in the physical task. This possibility is suggested by the difference in 
scalp distribution of the $\mathrm{P} 300$ probability effect across proportion conditions (see Figure 3). However, the distributional differences might at least in part be a result of some baseline problems in the high-proportion condition, with the larger baseline differences between the related and unrelated conditions at the frontal leads. These problems might have contributed to the distributional differences that were obtained. However, the distributional differences were not statistically significant. In the physical task, neither the Proportion $\times$ Electrode nor the Prime Type $\times$ Proportion $\times$ Electrode interaction approached significance. We are, therefore, very reluctant to assign strong interpretational relevance to this apparent distributional difference.

Regarding the overlap of $\mathrm{N} 400$ and P300 effects, the crucial question is whether the absence of an $\mathrm{N} 400$ priming effect in the physical task could be explained by an overlap of the N400 priming effect with the $\mathrm{P} 300$ probability effect. The presence of an $\mathrm{N} 400$ priming effect in these data is very unlikely. Based on the current literature on N400 priming effects, an underlying N400 priming effect could result from the following two scenarios.

Scenario 1 is that both in the high-proportion and in the lowproportion conditions a (small) N400 priming effect had been elicited in the physical task by the semantically related or unrelated items. In Scenario 1, we assume that this effect is of similar magnitude in both proportion conditions. This scenario leads to the prediction that the positive shift in the high-proportion condition is smaller than the positive shift in the low-proportion condition. The reason for this prediction is that in the former case the positive shift (as a function of probability) is for the same items as is the negative shift (as a function of relatedness). In the low-proportion condition, the positive shift is for the infrequent, related words and the larger negativity is for the frequent, unrelated targets. The resulting net effect should therefore be smaller in the case where negative and positive effects are for the same items (high proportion), as compared with the situation where the two effects are for different items (low proportion), thereby even increasing the net effect. However, no such difference in the size of the effects was observed. If there is a difference at all, it is in the opposite direction (overall positive shift of $2.3 \mu \mathrm{V}$ in the high-proportion condition and of $1.3 \mu \mathrm{V}$ in the low-proportion condition).

Scenario 2 is that just as for the lexical decision task, the hidden N400 priming effect in the high-proportion condition is larger than in the low-proportion condition. In that case, the cancellation effect for the high-proportion condition would have been even greater.

If there had been an overlap between $\mathrm{N} 400$ priming effects and $\mathrm{P} 300$ probability effects in the physical task, we expected it to have the predicted consequences on the basis of our knowledge about factors responsible for $\mathrm{N} 400$ priming effects. These consequences were not observed. Therefore, acknowledging the principled impossibility of excluding component overlap with surface recordings, the likelihood that overlap is responsible for the pattern of results observed is sufficiently low to warrant our conclusions.

A possible critique of the interpretation of the $\mathrm{P} 300$ effects in the physical task is that the absence of an N400 priming effect might arise from a baseline problem. This problem indeed might play a role in the high-proportion condition, where the waveforms for related and unrelated pairs separate very early in time (Figure 2). This difference in the baseline at least enhances the P300 probability effect. The reasoning here is that if the waveforms were forced to align, then an N400 priming effect might emerge and the P300 effect might disappear. It is indeed difficult to interpret the early onset of the effect, and the possibility cannot be discarded that the $\mathrm{P} 300$ probability effect in this condition might result from noise or baselining problems.

To check whether baseline problems might underly the observed effects, additional analyses were performed, in which a later baseline of 30-130 ms posttarget was used, thereby aligning the waveforms to counter their seemingly early separation. These ANOVAs revealed a significant interaction of Proportion $\times$ Relatedness for the P300 $(F[1,16]=4.81, p<.05)$ (latency epoch: $400-500 \mathrm{~ms}$ ) but not for the $\mathrm{N} 400$ (latency epoch: $300-400 \mathrm{~ms})$. Moreover, with the use of this baseline no main effect of relatedness was obtained for the early and the late latency epoch. The additional ANOVAs, therefore, strongly suggest that the $\mathrm{P} 300$ probability effect was not evoked by differences in baseline but is due to modulation of the P300 component.

\section{Conclusions}

Under shallow processing conditions, the amplitude of the P300 is sensitive to category probability, which in the present study was related to word and nonword stimuli. The dissociation between no reaction time differences for words and nonwords in the physical task, with P300 differences for these same stimuli, provides evidence that despite the shallow task requirements lexical information can still impact the ongoing analysis process. Under these conditions, however, the N400 is not sensitive to lexical information.

The amplitude of the N400 is modulated when semantic aspects of word stimuli enter into the episodic trace of wordlike stimulus events. However, automatic spreading of activation between related nodes in semantic memory does not appear to affect the N400. These results support the idea that within the context of normal language processing the $\mathrm{N} 400$ effect primarily reflects lexical integration processes.

\section{REFERENCES}

Becker, C. A. (1985). What do we really know about semantic context effects during reading? In D. Besner, T. G. Waller, \& E. M. MacKinnon (Eds.), Reading research: Advances in theory and practice (Vol. 5, pp. 125-169). Toronto: Academic.

Bentin, S., Kutas, M., \& Hillyard, S. A. (1993). Electrophysiologica evidence for task effects on semantic priming in auditory word processing. Psychophysiology, 30, 161-169.

Bentin, S., McCarthy, G., \& Wood, C. C. (1985). Event-related potentials associated with semantic priming. Electroencephalography and Clinical Neurophysiology, 60, 343-355.
Besson, M., Fischler, I., Boaz, T., \& Raney, G. (1992). Effects of automatic associative activation on explicit and implicit memory tests. Journal of Experimental Psychology: Learning, Memory, and Cognition, 18, 89-105.

Brown, C. M., \& Hagoort, P. (1993). The processing nature of the N400: Evidence from masked priming. Journal of Cognitive Neuroscience, 5, 34-44.

Brown, C. M., Hagoort, P., \& Chwilla, D. J. (1994). An event-related brain potential analysis of visual word priming effects. Manuscript submitted for publication. 
Campbell, K. B., Courchesne, E., Picton, T. W., \& Squires, K. C. (1979). Evoked potential correlates of human information processing. Biological Psychology, 8, 45-68.

Collins, A. M., \& Loftus, E. F. (1975). A spreading-activation theory of semantic processing. Psychological Review, 82, 407-428.

Connolly, J. F., Stewart, S. H., \& Phillips, N. A. (1990). The effects of processing requirements on neurophysiological responses to spoken sentences. Brain and Language, 39, 302-318.

Craik, F. I. M., \& Lockhart, R. S. (1972). Levels of processing: A framework for memory research. Journal of Verbal Learning and Verbal Behavior, 11, 671-684.

Deacon, D., Breton, F., Ritter, W., \& Vaughan, H. G., Jr. (1991). The relationship between the N2 and N400: Scalp distribution, stimulus probability, and task relevance. Psychophysiology, 28, 185-200.

De Groot, A. M. B. (1980). Mondelinge woordassociatienormen. Lisse, The Netherlands: Swets \& Zeitlinger.

De Groot, A. M. B. (1984). Primed lexical decision: Combined effects of the proportion of related prime-target pairs and the stimulus-onset asynchrony of prime and target. The Quarterly Journal of Experimental Psychology, 36A, 253-280.

De Groot, A. M. B. (1987). The priming of word associations: A levelsof-processing approach. The Quarterly Journal of Experimental Psychology, 39A, 721-756.

De Groot, A. M. B., \& de Bil, J. M. (1987). Nederlandse woordassociatienormen met reactietijden. Lisse, The Netherlands: Swets \& Zeitlinger

Duncan-Johnson, C. C., \& Donchin, E. (1977). On quantifying surprise: The variation in event-related potentials with subjective probability. Psychophysiology, 14, 456-467.

Fodor, J. A. (1983). The modularity of mind. Cambridge, MA: MIT Press.

Forster, K. I., \& Bednall, E. S. (1976). Terminating and exhaustive search in lexical access. Memory and Cognition, 4, 53-61.

Frauenfelder, U. H., \& Tyler, L. K. (1987). The process of spoken word recognition: An introduction. Cognition, 25, 1-20.

Greenhouse, S. W., \& Geisser, S. (1959). On methods in the analysis of profile data. Psychometrika, 24, 95-112.

Henderson, L. (1982). Orthography and word recognition in reading. London: Academic.

Holcomb, P. J. (1988). Automatic and attentional processing: An eventrelated brain potential analysis of semantic priming. Brain and Language, $35,66-85$.

Holcomb, P. J. (1993). Semantic priming and stimulus degradation: Implications for the role of the N400 in language processing. Psychophysiology, 30, 47-61.

Holcomb, P. J., \& Neville, H. J. (1990). Auditory and visual semantic priming in lexical decision: A comparison using event-related brain potentials. Language and Cognitive Processes, 5, 281-312.

Jacoby, L. L., \& Dallas, M. (1981). On the relationship between autobiographical memory and perceptual learning. Journal of Experimental Psychology: General, 110, 306-340.

Johnson, R., Jr. (1988). The amplitude of the P300 component of the event-related potential: Review and synthesis. In P. K. Ackles, J. R. Jennings, \& M. G. H. Coles (Eds.), Advances in psychophysiology (Vol. 3, pp. 69-137). Greenwich, CT: JAI.

Keefe, D. E., \& Neely, J. H. (1990). Semantic priming in the pronunciation task: The role of prospective prime-generated expectancies. Memory and Cognition, 18, 289-298.

Kutas, M., \& Hillyard, S. A. (1980). Reading senseless sentences: Brain potentials reflect semantic incongruity. Science, 207, 203-205.

Kutas, M., \& Hillyard, S. A. (1984). Brain potentials during reading reflect word expectancy and semantic association. Nature, 307, 161-163.

Kutas, M., \& Hillyard, S. A. (1989). An electrophysiological probe of incidental semantic association. Journal of Cognitive Neuroscience, I, 38-49.
Kutas, M., Lindamood, T., \& Hillyard, S. A. (1984). Word expectancy and event-related potentials during sentence processing. In S. Kornblum \& J. Requin (Eds.), Preparatory states and processes (pp. $217-$ 238). Hillsdale, NJ: Erlbaum.

Kutas, M., \& Van Petten, C. (1988). Event-related brain potential studies of language. In P. K. Ackles, J. R. Jennings, \& M. G. H. Coles (Eds.), Advances in psychophysiology (Vol. 3, pp. 139-187). Greenwich, CT: JAI.

Lauteslager, M., Schaap, T., \& Schievels, D. (1986). Schriftelijke woordassociatienormen voor 549 nederlandse zelfstandige naamwoorden. Lisse, The Netherlands: Swets \& Zeitlinger.

Marslen-Wilson, W. D. (1989). Access and integration: Projecting sound onto meaning. In W. D. Marslen-Wilsen (Ed.), Lexical representation and process. Cambridge, MA: MIT Press.

McCarthy, G., \& Wood, C. C. (1985). Scalp distribution of event-related potentials: An ambiguity associated with analysis of variance models. Electroencephalography and Clinical Neurophysiology, 69, 218-233.

Meyer, D. M., \& Schvaneveldt, R. W. (1971). Facilitation in recognizing pairs of words: Evidence of a dependence between retrieval operations. Journal of Experimental Psychology, 90, 227-234.

Mitchell, P. F., Andrews, S., Fox, A. M., Catts, S. V., Ward, P. B., \& McConaghy, N. (1991). Active and passive attention in schizophrenia: An ERP study of information processing in a linguistic task. Biological Psychology, 32, 101-124.

Neely, J. H. (1991). Semantic priming effects in visual word recognition: A selective review of current findings and theories. In D. Besner \& G. Humphreys (Eds.), Basic processes in reading: Visual word recognition (pp. 264-336). Hillsdale, NJ: Erlbaum.

Neely, J. H., \& Keefe, D. E. (1989). Semantic context effects on visual word processing: A hybrid prospective-retrospective processing theory. In G. H. Bower (Ed.), The psychology of learning and motivation: Advances in research and theory (Vol. 24, pp. 207-248). New York: Academic.

Oldfield, R. C. (1971). The assessment and analysis of handedness: The Edinburgh Inventory. Neuropsychologia, 9, 97-113.

Posner, M. I., \& Snyder, C. R. R. (1975). Attention and cognitive control. In R. L. Solso (Ed.), Information processing and cognition: The Loyola symposium (pp. 55-85). Hillsdale, NJ: Erlbaum.

Renault, B., Signoret, J., Debruille, B., Breton, F., \& Bolgert, F. (1989). Brain potentials reveal covert facial recognition in prosopagnosia. Neuropsychologia, 29, 905-912.

Rösler, F., Heil, M., \& Glowalla, U. (1993). Monitoring retrieval from long-term memory by slow event-related brain potentials. Psychophysiology, 30, 170-182.

Rugg, M. D., Furda, J., \& Lorist, M. (1988). The effects of task on modulation of event-related potentials in word repetition. Psychophysiology, 25, 55-63.

Schulman, H. G., \& Davison, T. C. B. (1977). Control properties of semantic coding in a lexical decision task. Journal of Verbal Learning and Verbal Behavior, 16, 91-98.

Smith, M. C., Theodor, L., \& Franklin, P. E. (1983). The relationship between contextual facilitation and depth of processing. Journal of Experimental Psychology: Learning, Memory, and Cognition, 9, 697-712.

Uit den Boogaart, P. C. (1975). Woordfrequenties in geschreven en gesproken Nederlands. Oosthoek, The Netherlands: Scheltema \& Holkema.

Winer, B. J. (1971). Statistical principles in experimental design. New York: McGraw-Hill.

Zwitserlood, P. (1989). The locus of the effects of sentential-semantic context in spoken-word processing. Cognition, 32, 25-64.

(Received March 16, 1993; Accepted June 24, 1994) 
APPENDIX

\begin{tabular}{|c|c|c|c|c|c|c|c|c|}
\hline Related word pairs & $\mathrm{ms}$ & Unrelated word pairs & $\cdot$ & & $\mathrm{ms}$ & & & \\
\hline 1. ader-bloed & 471 & zweet-tekst & & & 471 & & & \\
\hline 2. bakker-brood & 457 & kachel-sport & & & 457 & & & \\
\hline 3. been-arm & 539 & stof-veilig & & • & 543 & & & \\
\hline 4. donker-licht & 474 & sjaal-grond & & & 477 & & & \\
\hline 5. gebouw-flat & 529 & honger-struik & " & & 528 & & & \\
\hline 6. dol-gek & 510 & wraak-lip & & & 515 & & & \\
\hline 7. storm-wind & 496 & tuig-wand & & & 495 & & & \\
\hline 8. links-rechts & 488 & vreten-post & & & 490 & & & \\
\hline 9. matroos-schip & 520 & doel-buik & & & 515 & & & \\
\hline 10. chef-baas & 566 & uitval-slang & & & 563 & & & \\
\hline 11. bal-rond & 498 & accu-jeugd & & & $499^{\circ}$ & & & \\
\hline 12. dag-nacht & 510 & akker-grijs & & & 514 & & & \\
\hline 13. kust-zee & 463 & strak-punt & & & 459 & & & \\
\hline 14. laken-bed & 472 & afwas-fiets & & & 476 & & & \\
\hline 15. lang-kort & 500 & kwart-gezin & & & 500 & $\cdot$ & - & \\
\hline 16. haai-vis & 523 & pakket-dak & & & 525 & & 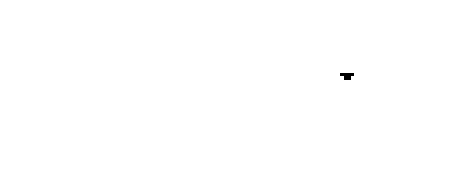 & 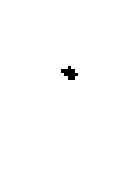 \\
\hline 17. faam-roem & 509 & paleis-aap & & & 508 & & $i$ & . \\
\hline 18. dier-beest & 473 & keer-kind & & & 472 & & & r \\
\hline 19. groen-gras & 482 & puinhoop-wolf & & & 482 & & & \\
\hline 20. misdaad-moord & 502 & monnik-trap & & & 506 & & & \\
\hline 21. dorp-stad & 515 & natie-lol & & & 519 & $\checkmark$ & $\cdot$ & \\
\hline 22. gooien-werpen & 578 & koek-traag & & & 579 & & & \\
\hline 23. drempel-deur & 493 & perron-spuit & & & 490 & & & \\
\hline 24. levend-dood & 467 & elpee-neus & & & 469 & & & \\
\hline 25. ster-hemel & 530 & paniek-blouse & & & 539 & & & \\
\hline 26. berouw-spijt & 506 & liefde-hol & & & 508 & & & \\
\hline 27. antwoord-vraag & 524 & kapper-meer & & & 526 & & & \\
\hline 28. kil-koud & 461 & ui-slot & & & 457 & & & \\
\hline 29. aardig-lief & 530 & woord-zak & & & 530 & & . & \\
\hline 30. hond-kat & 492 & gelei-taal & & & 489 & & & \\
\hline 31. bes-vrucht & 514 & schedel-taxi & & & 509 & & & - \\
\hline 32. leeg-vol & 503 & boer-kreet & & & 506 & & $\cdot \quad-$ & \\
\hline 33. man-vrouw & 491 & rot-vrij & & & 489 & & & \\
\hline 34. koorts-ziek & 507 & stel-pers & & & 512 & & & \\
\hline 35. raak-mis & 532 & rots-passen & & & 532 & & & \\
\hline 36. bij-honing & 529 & put-spot & & & 526 & & & \\
\hline 37. beven-trillen & 544 & nevel-lek & & & 541 & r & & \\
\hline 38. prei-groente & 490 & geluid-jurk & & $\cdot$ & 487 & & & \\
\hline 39. papier-pen & 519 & vak-steek & & & 515 & & $\cdot$ & \\
\hline 40. venster-raam & 516 & kilo-minuut & & & 519 & & . & \\
\hline \multicolumn{9}{|l|}{ Reaction time } \\
\hline$M$ & 505.6 & & & & 505.9 & & & \\
\hline$S D$ & 27.6 & & & & 28.0 & & & \\
\hline \multicolumn{9}{|l|}{ Language frequency } \\
\hline$M$ & 82.9 & $\cdot$ & & . & 61.5 & & & \\
\hline$S D$ & 108.5 & & & & 105.9 & & & \\
\hline
\end{tabular}

